\title{
Response of Caterpillar Pests and the Parasite Diadegma insulare to Collard Cultivars and a Pyrethrin Insecticide
}

\author{
J. M. Schalk ${ }^{1}$ \\ U.S. Department of Agriculture, Agricultural Research Service, U.S. Vegetable \\ Laboratory, 2875 Savannah Highway, Charleston, SC 29414-5334
}

B.M. Shepard ${ }^{2}$

Clemson University Coastal Research and Education Center, 2865 Savannah Highway, Charleston, SC 29414

\section{K.A. Stoner ${ }^{3}$}

The Connecticut Agricultural Experiment Station, 123 Huntington Street, New Haven, CT 06504

Additional index words. Brassicae oleracea var acephala, Plutella xylostella, Pieris rapae,

Trichoplusia ni, Diadegma insulare

Abstract. There were no differences in mortality, plant preference, or plant damage when diamondback moth (DBM) (Plutella xylostella L.) larvae were tested in no-choice and freechoice tests using leaf disks of resistant ('Green Glaze') or susceptible ('Vates', standard commercial cultivar) collards (Brassica oleracea Acephala group). No residuals of the pyrethrin insecticide Asana-XL (esfenvalerate) were detected 6 days after its application when DBM larvae were exposed to excised foliage for $\mathbf{7 2}$ hours. In a field test, more imported cabbage worm (ICW) (Pieris rapae $\mathrm{L}$.) eggs were found on 'Vates' treated with the insecticide than on nontreated Vates' or nontreated or treated 'Green Glaze'. The fewest ICW, cabbage looper (CL) (Trichoplusia ni Hubner), and DBM larvae were found on the insecticide-treated cultivars. Fewer caterpillars were found on 'Green Glaze' than Yates'. An additive effect of plant resistance and insecticide application lowered counts of DBM, ICW, and CL larvae. Percent parasitism of DBM by Diadegma insulare Cresson (Hymenoptera: Ichneumonidae) was lower on cultivars treated with the insecticide. Field plant damage ratings were higher for nontreated 'Vates' and lowest for treated cultivars, but nontreated 'Green Glaze' had a significantly lower feeding damage rating than nontreated 'Vates'. Chemical name used: (S)-cyano (3-phenoxy phenyl) methyl-(S)-4 chloro-alpha (1-methylethyl) benzeneacetate [esfenvalerate (Asana-XL)].

The most important group of insect pests of Brassica crops in the southeastern United States is the caterpillar complex consisting mainly of the diamondback moth (DBM), imported cabbage worm (ICW), and cabbage looper (CL). $\mathrm{DBM}$ is particularly troublesome because of its resistance to insecticides (Shelton and Wyman, 1992; Sun et al., 1986) and Bacillus thuringiensis (BT) (Tabashnik et al., 1992).

Commercial growers in South Carolina routinely treat their collard crops during the growing season with chemical insecticides or BT. Brassica crops resistant to this caterpillar complex have not been identified for use in this area.

Recently, a glossy-leaved Brassica genotype (PI-234599) has shown resistance to DBM (Dickson and Eckenrode, 1980; Lin et al.,

Received for publication 11 Aug. 92. Accepted for publication 4 Dec. 1992. The cost of publishing this paper was defrayed in part by the payment of page charges. Under postal regulations, this paper therefore must be hereby marked advertisement solely to indicate this fact.

${ }^{1}$ Research Entomologist.

${ }^{2}$ Resident Director, Professor of Entomology.

${ }^{3}$ Assistant Entomologist
1983, 1984). Stoner (1990) found that glossyleaved lines of broccoli (B. oleracea Italica group), cauliflower ( $B$. oleracea Botrytis group), brussels sprouts (B. oleracea Gemmifera group), collards, and kale ( $B$, oleracea Alboglabra group) consistently had fewer ICW eggs and larvae and cabbage aphids (Brevicoryne brassicae L.) than other lines. Resistance of PI 234599 and several other glossy-leaved Brassica to DBM was attributed to leaf wax associated with the glossy trait. In a field test using artificial infestation, Eigenbrode et al. (1991) reported fewer firstinstar DBM larvae $48 \mathrm{~h}$ after hatching on 'Green Glaze' than 'Vates' leaves. Also, in a 5-min test of movement of newly hatched DBM under laboratory conditions, Eigenbrode et al. (199 1) found faster movement on 'Green Glaze' than 'Vates' leaves. This speed was similar to that associated with resistance to DBM in other glossy Brassica lines (Eigenbrode and Shelton, 1990; Eigenbrode et al., 1991).

We tested 'Green Glaze' and 'Vates' for susceptibility to DBM in the laboratory and to DBM, ICW, and CL in the field. We also determined the response of the caterpillar complex and DBM parasite Diadegma insulare L.
(Hymenoptera) to the pyrethrin insecticide Asana-XL applied to both cultivars in the field.

'Green Glaze', previously tested by Stoner et al. (1990), was obtained from Alf Christianson Seed Co., Mount Vernon, Wash. 'Vates' was obtained from a local seed distributor in Charleston, S.C.

Laboratory tests. All experiments were conducted in a rearing room at $26 \pm 5 \mathrm{C}$ and a 16-h photoperiod. Insects were reared in the laboratory on a modified diet from Hou (1986). The first test determined DBM mortality when larvae were confined to field-collected 'Green Glaze' and 'Vates' leaf disks with and without Asana-XL. Single-leaf disks $(6.5 \mathrm{~cm}$ in diameter) of each cultivar were collected from the field 6 days after Asana-XL was applied and placed singly into $10-\mathrm{cm}$-diameter petri dishes containing filter paper moistened with water. Ten first-instar larvae were placed on each leaf disk. Larval mortality and plant damage were recorded after $72 \mathrm{~h}$. Ten replicates (one disk per plant) were arranged in a completely randomized design. Damage to leaf disks was assessed using a rating scale from 1 to 5 , where $1=$ no damage and $5=$ severe damage.

The second trial tested DBM larval preference. Ten first-instar larvae were placed in the center of each 10-cm-diameter petri dish containing two leaf disks ( $2 \mathrm{~cm}$ in diameter) each of 'Green Glaze' and 'Vates' arranged alternately in a circular pattern on moist filter paper. The test was replicated four times. Larval mortality and cultivar selection were recorded at 2, 4, 19, and $24 \mathrm{~h}$, and disk damage was rated after $24 \mathrm{~h}$.

Field test. 'Green Glaze' and 'Vates' were planted in the field in a completely randomized-block design. Each treatment was replicated four times. Each plot was $9.1 \times 10.9 \mathrm{~m}$ and had 10 rows $91 \mathrm{~cm}$ apart. Plants in rows were $46 \mathrm{~cm}$ apart (120 plants/plot). One-half of each plot was sprayed weekly with Asana$\mathrm{XL}$ at $40 \mathrm{~g}$ a.i./ha. Companion plots of both cultivars were not treated. Asana-XL was applied six times $(8,17$, and $24 \mathrm{Apr}$. and 1, 8, and 14 May), and sampling was conducted weekly (8, 15, 22, and 29 Apr. and 6, 13, and21 May) from each of 10 flagged sites in each plot. A clockwise sampling pattern around each flagged area was used to avoid sampling the same plant each week. CL, DBM, and ICW larvae, ICW eggs, and $D$. insulare pupae were counted. Plant damage just before harvest was rated from 0 to 4 , where $0=$ no damage, $1=$ slight damage to outer leaves, 2 = slight damage to inner and outer leaves, $3=$ moderate damage to inner or outer leaves or both, and 4 $=$ severe damage.

The percentage of parasitized DBM was calculated using the formula percent parasitized DBM = number of $D$. insulare-parasitized DBM $\times 100 /$ number of DBM pupae + number of $D$. insulare-parasitized DBM.

Laboratory tests. We detected no differences in larval mortality $(0.1 \pm 0.3 \mathrm{SD}$, 'Green Glaze'; 0.0, 'Vates') or leaf disk damage (3.5 \pm 0.7 SD, 'Green Glaze'; $3.8 \pm 0.7$ sD, 'Vates') between the two cultivars in test 1 . Similarly, test 2 yielded no differences in cultivar prefer- 
ence $(4.3 \pm 0.9$ SD, 'Green Glaze'; $3.8 \pm 1.1$ SD, 'Vates') or leaf disk damage (1.3 $\pm 0.6 \mathrm{SD}$, 'Green Glaze'; 1.3 土. 0.4 sD, 'Vates'). Thus, no antibiosis, preference, or difference in damage was detected under the conditions of our experiment. Why these differences in field and short-term laboratory tests were not reflected in our longer-term laboratory tests is not known. However, the failure of the survival and preference bioassays to detect differences between 'Vates' and 'Green Glaze' is similar to the results of Eigenbrode and Shelton (1990) and Lin et al. (1983). Glossy-leaved resistanceregardless of genetic source-apparently cannot be assessed with this type of assay.

Field test. More ICW eggs were found on 'Vates' leaves treated with Asana-XL than on nontreated 'Vates' leaves or on treated or nontreated 'Green Glaze' leaves (Fig. 1A, Table 1), possibly due to predator elimination, oviposition preference, or oviposition stimulation in those cultivars treated with AsanaXL (Chelliah and Heinrichs, 1980). However, most ICW larvae were found on nontreated 'Vates' (Fig. 1B, Table 1). Fewest ICW larvae were found on 'Green Glaze' and 'Vates' treated with Asana-XL, while nontreated

Table 1. Mean season-long number of larvae per plant of diamondback moth (DBM), cabbage looper (CL), and eggs and larvae of imported cabbage worm (ICW) and plant damage ratings of pyrethrin-treated and nontreated 'Green Glaze' and 'Vates' collard grown in Charleston, S.C., 1991.

\begin{tabular}{|c|c|c|c|c|c|c|}
\hline \multirow[b]{2}{*}{ Cultivar } & \multirow[b]{2}{*}{ Treatment } & \multirow{2}{*}{$\begin{array}{c}\text { ICW } \\
\text { eggs/plant } \\
\text { (no.) }\end{array}$} & \multicolumn{3}{|c|}{$\begin{array}{l}\text { Larvae/plant } \\
\text { (no.) }\end{array}$} & \multirow{2}{*}{$\begin{array}{c}\text { Plant }^{z} \\
\text { damage }\end{array}$} \\
\hline & & & DBM & $\mathrm{CL}$ & ICW & \\
\hline \multirow{2}{*}{$\overline{\text { Vates }}$} & None & $0.36 \mathrm{~b}$ & $0.40 \mathrm{a}^{y}$ & $0.45 \mathrm{a}$ & $0.55 \mathrm{a}$ & $2.8 \mathrm{a}$ \\
\hline & Asana-XL & $0.55 \mathrm{a}$ & $0.23 \mathrm{~b}$ & $0.07 \mathrm{c}$ & $0.29 \mathrm{~b}$ & $1.25 \mathrm{c}$ \\
\hline \multirow[t]{2}{*}{ Green Glaze } & None & $0.22 \mathrm{~b}$ & $0.20 \mathrm{~b}$ & $0.25 \mathrm{~b}$ & $0.30 \mathrm{~b}$ & $1.97 \mathrm{~b}$ \\
\hline & Asana-XL & $0.22 \mathrm{~b}$ & $0.14 \mathrm{~b}$ & $0.05 \mathrm{c}$ & $0.10 \mathrm{c}$ & $1.12 \mathrm{c}$ \\
\hline
\end{tabular}

${ }^{x}$ Rating from 0 to 4 , where $0=$ no damage, $1=$ slight damage to outer leaves, $2=$ slight damage to inner and outer leaves, $3=$ moderate damage to inner or outer leaves or both, and $4=$ severe damage. ${ }^{\gamma}$ Mean separation in columns by LSD, $P \leq 0.10$.

'Green Glaze' had intermediate counts (Table 1). However, there were significantly fewer ICW larvae on nontreated 'Green Glaze' than nontreated 'Vates'.

As with ICW, CL larval population density was lower on 'Green Glaze' treated with Asana$\mathrm{XL}$, highest on nontreated 'Vates', and intermediate on treated 'Vates' and nontreated 'Green Glaze' leaves (Fig. 2, Table 1). Also, fewer CL larvae were found on nontreated 'Green Glaze' than on nontreated 'Vates' leaves (Table 1). Thus, CL populations on
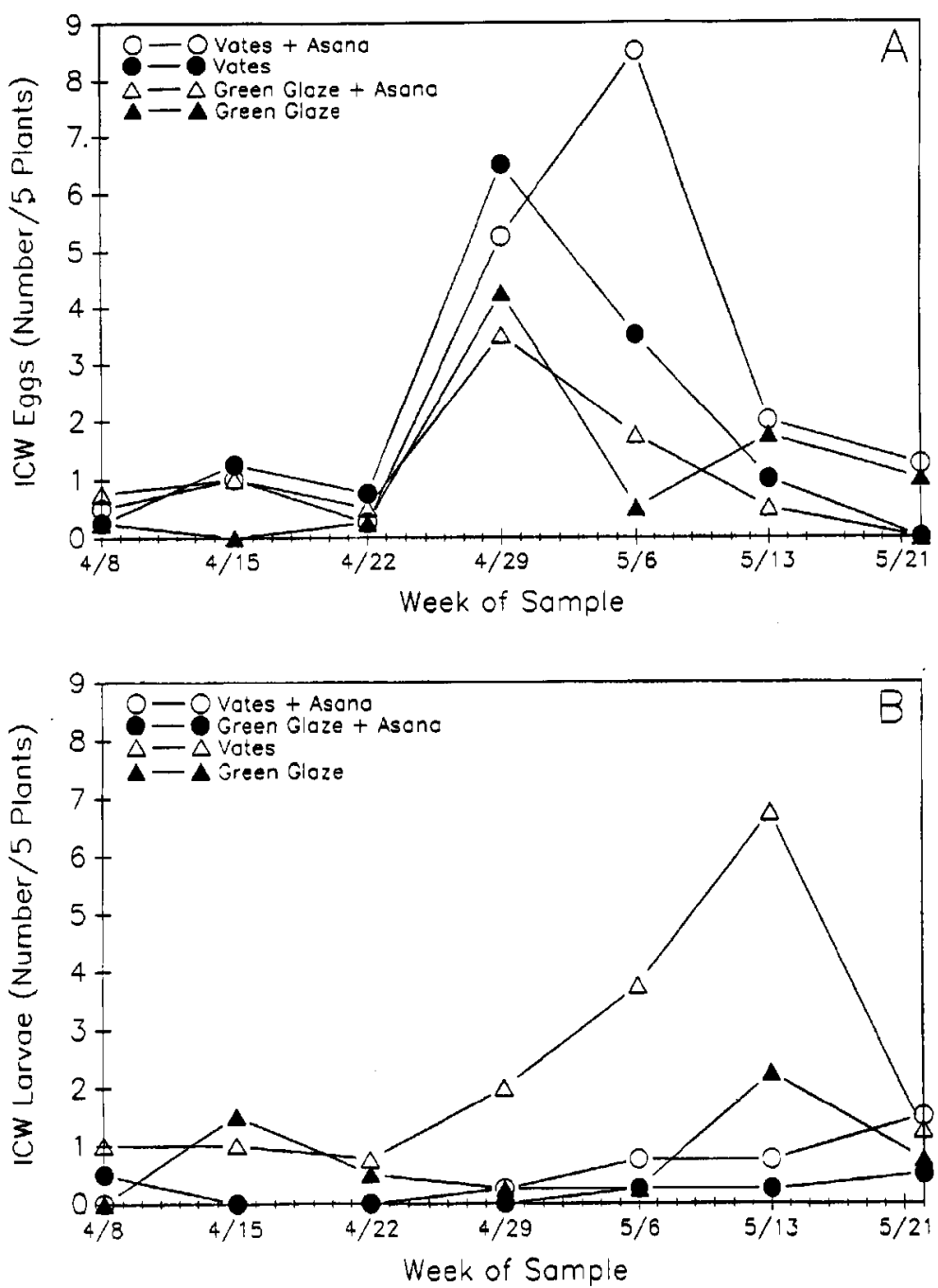

Fig. 1. Mean number of imported cabbage worm per five plants per week on resistant 'Green Glaze' and susceptible 'Vates' collard treated with the pyrethrin Asana-XL or not treated; (A) eggs, (B) larvae. nontreated 'Green Glaze' were equal to those on treated 'Vates' leaves.

DBM reached a peak population of six per five plants on nontreated 'Vates' on 29 Apr. and resurged to about five per five plants on 13 May on treated 'Vates'. The season-long average number of DBM was highest on nontreated 'Vates' and lowest on treated and nontreated 'Green Glaze' plants (Table 1, Fig. 3). Similar to $\mathrm{CL}, \mathrm{DBM}$ population densities on nontreated 'Green Glaze' and treated 'Vates' plants were the same. For both cultivars, percentage parasitism by $D$. insulare was the same $(x=4.5 / 5$ plants $)$ in nontreated but lower $(\mathrm{x}=1.0 / 5$ plants) in treated plants (difference significant at $P<0.05$ ).

In general, fewer of all three caterpillar species were found on 'Green Glaze' than 'Vates' (Table 1), and there was an additive effect of plant resistance and insecticide treatments for DBM, ICW, and CL larvae.

Plant damage was highest in nontreated 'Vates' and lowest in treated 'Green Glaze' and treated 'Vates' (Table 1). 'Green Glaze' had intermediate levels of damage.

In summary, it is likely that using insectresistant 'Green Glaze' would reduce the number of insecticide applications required to control the caterpillarpests we studied. A program that monitors insect populations in the field and applies specific insecticides would be an effective insect pest management program for collard.

\section{Literature Cited}

Cheliah, S., L. Fabellar, and E.A. Heinrichs. 1980. Effects of sublethal doses of three insecticides on the reproductive rate of the brown planthopper, Nilaparvata lugens, on rice. Environ. Entomol. 9:778-780.

Dickson, M.H. and C.J. Eckenrode. 1980. Breeding for resistance in cabbage and cauliflower to cabbage looper, imported cabbageworm, and diamondback moth. J. Amer. Soc. Hort. Sci. 105:782-785.

Eigenbrode, S.D. and A.M. Shelton. 1990. Behavior of neonate diamondback moth larvae on glossyleafed resistant Brassica oleracea L. Environ. Entomol. 19:1566-1571.

Eigenbrode, S.D., K.A. Stoner, A.M. Shelton, and W.C. Kain. 1991. Characteristics of glossy leaf waxes associated with resistance to diamondback moth (Lepidoptera: Plutellidae) in Brassica oleracea. J. Econ. Entomol. 84:1609-1618.

Hou, R.F. 1986. Mass rearing of diamond back moth, p. 89-95. In: N.S. Talekar (ed.). Diamondback 


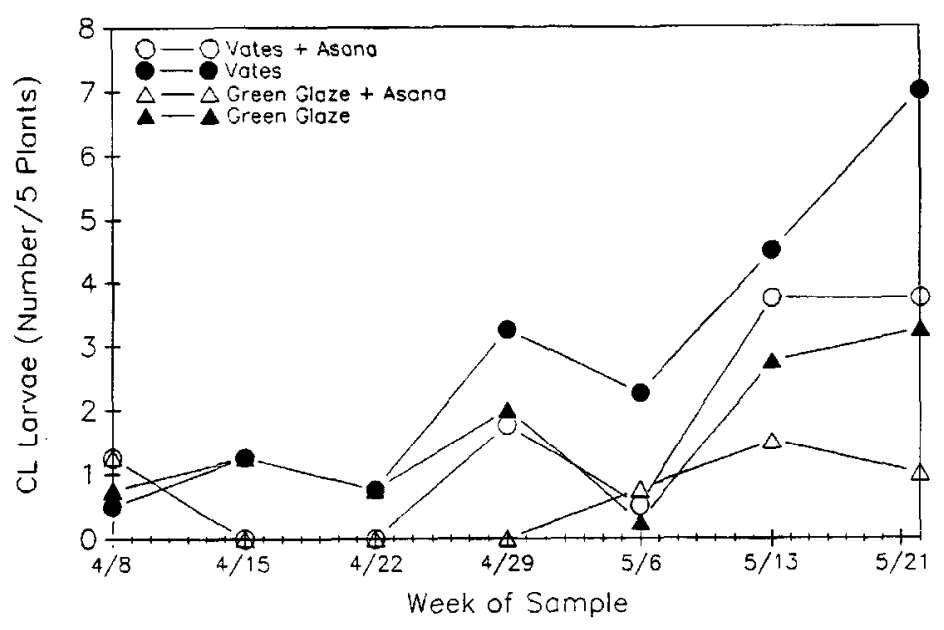

Fig. 2. Mean number of cabbage looper larvae per five plants per week on resistant 'Green Glaze' and susceptible 'Vates' collard treated with the pyrethrin insecticide Asana-XL or not treated.

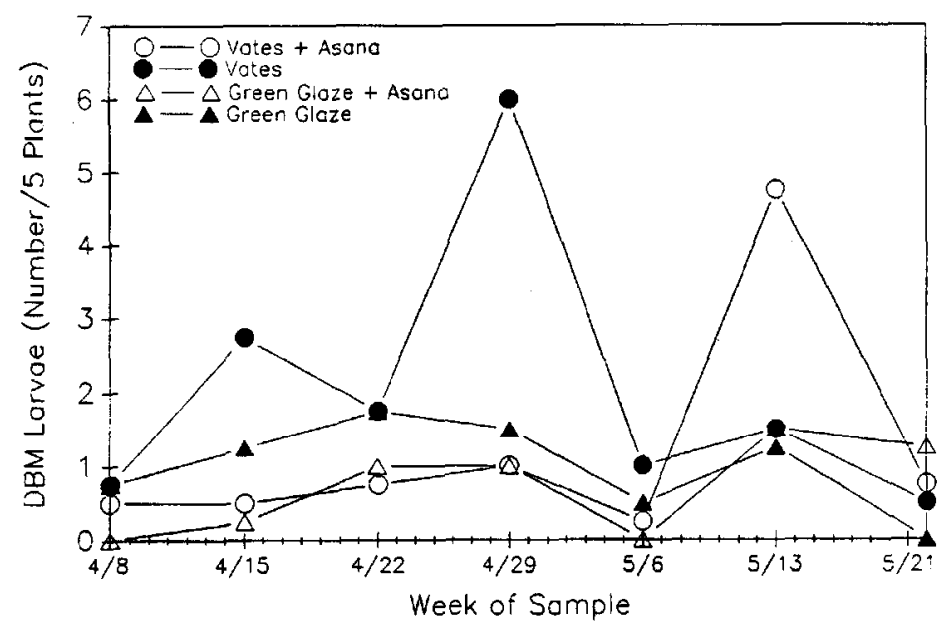

Fig. 3. Mean number of diamondback moth larvae per five plants per week on resistant 'Green Glaze' and susceptible 'Vates' collard treated with the pyrethrin insecticide Asana-XL or not treated. moth management. Asian Veg. Res. \& Dev. Ctr., Shanhua, Taiwan. Publ. 92-368.

Lin, J., M.H. Dickson, and C.J. Eckenrode. 1984. Resistance of Brassica lines to the diamondback moth (Lepidoptera: Y ponomeutidae) in the field and inheritance of resistance. J. Econ. Entomol. 77:1293-1296.

Lin, J., C.J. Eckenrode, and M.H. Dickson. 1983. Variation in Brassica oleracea resistance to diamondback moth. J. Econ. Entomol. 76: 14231427.

Shelton, A. and J.A. Wyman. 1992. Insecticide resistance of diamondback moth in North America, p. 447-454. In: N.S. Talekar (ed.). Diamondback moth and other crucifer pests: Proceedings of the second international workshop. Asian Veg. Res. \& Dev. Ctr., Shanhua, Taiwan. Publ. 92-368.

Stoner, K.A. 1990. Glossy leaf wax and plant resistance to insects in Brassica oleracea under natural infestation. Environ. Entomol. 19:730-739.

Sun, C.N., T.K. Wu, J.S. Chen, and W.T. Lee. 1986. Insecticide resistance in the diamondback moth, p. 359-372. In: N.S. Talekar and T.D. Griggs (eds.). Diamondback moth management: Proceedings of the first international workshop. Asian Veg. Res. \& Dev. Ctr., Shanhua, Taiwan. Publ. 92-368.

Tabashnik, B.E., N. Finson, J.M. Schwartz, M.A. Caprio, and M.W. Johnson. 1992. Diamondback mothresistance to Bacillus thuringiensis in Hawaii, p. 175-183. In: N.S. Talekar (ed.). Diamondback moth and other crucifer pests: Proceedings of the second international workshop. Asian Veg. Res. \& Dev. Ctr., Shanhua, Taiwan. Publ. 92-368. 